\title{
Antioxidant Activities of Commiphora leptophloeos (Mart.) J. B. Gillett) (Burseraceae) Leaf Extracts Using In Vitro and In Vivo Assays
}

\author{
Maria Lúcia da Silva Cordeiro, ${ }^{1}$ Ana Raquel Carneiro Ribeiro, ${ }^{1}$ \\ Luciana Fentanes Moura de Melo, ${ }^{1}$ Lucas Felipe da Silva, ${ }^{1}$ Gabriel Pereira Fidelis, ${ }^{2}$ \\ Larissa Marina Pereira Silva, ${ }^{3}$ Ricardo Basílio de Oliveira Caland, ${ }^{4}$ \\ Cesar Orlando Muñoz Cadavid, ${ }^{4}$ Cícero Flavio Soares Aragão, ${ }^{5}$ Silvana Maria Zucolotto, ${ }^{3}$ \\ Riva de Paula Oliveira, ${ }^{4}$ Deborah Yara Alves Cursino dos Santos, ${ }^{6}$ \\ Hugo Alexandre Oliveira Rocha, ${ }^{2}$ and Katia Castanho Scortecci ${ }^{1}{ }^{1}$
}

${ }^{1}$ Laboratório de Transformação de Plantas e Análise em Microscopia (LTPAM), Departamento de Bioquímica, Universidade Federal do Rio Grande do Norte (UFRN), Natal 59078-970, Brazil

${ }^{2}$ Laboratório de Biotecnologia de Polímeros Naturais (BIOPOL), Departamento de Bioquímica, Universidade Federal do Rio Grande do Norte (UFRN), Natal 59078-970, Brazil

${ }^{3}$ Laboratório de Produtos Naturais e Bioativos (PNBio), Departamento de Farmácia, Universidade Federal do Rio Grande do Norte (UFRN), Natal 59010-180, Brazil

${ }^{4}$ Laboratório de Genética Bioquímica (LGB), Departamento de Biologia Celular e Genética, Universidade Federal do Rio Grande do Norte (UFRN), Natal 59078-970, Brazil

${ }^{5}$ Laboratório de Controle de Qualidade de Medicamentos (LCQMed), Departamento de Farmácia, Universidade Federal do Rio Grande do Norte (UFRN), Natal 59010-180, Brazil

${ }^{6}$ Laboratório de Fitoquímica, Departamento de Botânica, Universidade de São Paulo (USP), São Paulo 05508-090, Brazil

Correspondence should be addressed to Katia Castanho Scortecci; kacscort@yahoo.com

Received 14 April 2020; Revised 3 March 2021; Accepted 3 April 2021; Published 24 April 2021

Academic Editor: Maria R. Ciriolo

Copyright (c) 2021 Maria Lúcia da Silva Cordeiro et al. This is an open access article distributed under the Creative Commons Attribution License, which permits unrestricted use, distribution, and reproduction in any medium, provided the original work is properly cited.

Commiphora leptophloeos is widely used in folk medicine without any scientific basis. Considering this, the aim of this study was to evaluate the chemical profile and the antioxidant activity of $C$. leptophloeos leaf extracts using in vitro and in vivo assays. Six extracts were obtained from fresh leaves using a serial extraction (nonpolar to polar solvents). These extracts were first evaluated with the presence of phytochemical compounds using the methods thin layer chromatography (TLC), ultrahigh performance liquid chromatography (UHPLC-DAD), and high performance liquid chromatography, both with diode array detection (HPLC-DAD). Based on the compounds identified, it was used some bioinformatics tools in order to identify possible pathway and gene targets. After that, the antioxidant capacity from these extracts was analysed by in vitro assays and in vivo assays using Caenorhabditis elegans model. Phytochemical analyses showed the presence of polyphenols, such as rutin, vitexin, and quercetin diglycosides in all extracts, especially in ethanol extract (EE) and methanol extract (EM). Bioinformatics analysis showed these polyphenols linked to antioxidant pathways. Furthermore, EE and EM displayed a high antioxidant capacity in DPPH and superoxide radical scavenging assays. They also had no effect on cell viability for 3T3 nontumour cell. However, for B16-F10 tumour cell lines, these extracts had toxicity effect. In vivo assays using C. elegans N2 showed that EE was not toxic, and it did not affect its viability nor its development. Besides, EE increased worm survival under oxidative stress and reduced intracellular reactive oxygen species (ROS) levels by $50 \%$. Thus, C. leptophloeos EE displayed an important in vitro and in vivo antioxidant capacity. The EE extract has polyphenols, suggesting that these compounds may be responsible for a myriad of biological activities having this potential to be used in various biotechnological applications. 


\section{Introduction}

Medicine plants have a millenary practice in some cultures [1]. It is known that plants produce different intermediate compounds (phenolic compounds, terpens, and alkaloids), and these compounds may have a pharmacology activity like antioxidant role, anticancer agent, and dietary supplementation [2]. According to Newman and Cragg [3] from the period from 1981 to 2014, half of the new molecules approved were originated from medicinal plants. Due to this, medicinal plants have been receiving a special attention in order to identify new bioactive molecules that may be used in medicine for the different diseases such as antioxidant, antimicrobial, antiproliferative, antifungal, antiparasitic, and immunomodulatory $[4,5]$.

Many age-related and chronic illnesses like diabetes, cardiovascular disease, Parkinson's disease, Alzheimer's disease, inflammatory diseases, and cancer have been associated with oxidative stress due to an imbalance between reactive oxygen species (ROS) production and degradation, consequently increasing the ROS levels [6,7]. Plant phenolic compounds are known as potent antioxidants, which are crucial for the maintenance of redox homeostasis $[4,6,7]$.

Commiphora leptophloeos (Mart.) J. B. Gillett. (Burseraceae) is a native species from Caatinga, an exclusive Brazilian biome characterised by low water availability, high temperatures, and high light. Pereira et al. [8] reported on the antimicrobial activity of methanol extract obtained from barks of this plant. However, no data pertaining to its chemical profile and potential antioxidant effects exist. Therefore, the chemical profile of C. leptophloeos leaf extracts and the antioxidant activity was investigated in this study, by in vitro and in vivo assays using antioxidant assays, the 3T3 and B16F10 cell lines as well as the C. elegans worms.

\section{Materials and Methods}

2.1. Reagents. Potassium ferricianyde (702587), ferrous sulfate II, trichloroacetic acid, Folin-Ciocalteu reagent, sulfuric acid, and Folin-Ciocalteu reagente (109001) were purchased from Merck (Darmstadt, Germany). Nitro blue tetrazolium (NBT), monosaccharides, ethylenediaminetetraacetic acid (EDTA) (E9884), D-glucose (5767), gallic acid (G7384), ascorbic acid (A5960), bovine serum albumin protein (BSA), methionine (M9625), 3-(4,5-dimethylthiazolyl-2)-2,5-diphenyltetrazolium bromide (MTT-M2128), sodium phosphate (S7907), pyrocatechol violet (P7884), riboflavin (R9504), ammonium molybdate, 2,7-dichlorofluorescein (H2DCFDA-D6883), and tert-butyl hydrogen peroxide ( $\mathrm{t}-\mathrm{BOOH}-458139)$ were purchased from Sigma-Aldrich Co. (St. Louis, MO, USA). DPPH (2,2-diphenyl-1-picrylhydrazyl) were purchased from Fluka (Seelze, Germany). Dimethylsulphoxide (DMSO) were purchased from CRQ (São Paulo, Brazil). Sodium bicarbonate, nonessential amino acids, and phosphate-buffered saline (PBS) were purchased from Invitrogen Corporation (Burlington, ON, Canada). Dulbeccos modified Eagles medium (DMEM) and fetal bovine serum (FBS) were obtained from CULTILAB (Campinas, SP, Brazil). Penicillin and streptomycin were obtained from Gibco (Fort Worth, TX, USA). All other solvents and chemicals were of analytical grade from Synth, Diadema, SP, Brazil. The stan- dards used in the HPLC-DAD and UPLC-DAD were 3hydroxicinnamic acid (501-52-0), benzoic acid (65-85-0), caffeic acid (331-39-5), cinnamic acid (621-82-9), chlorogenic acid (327-97-9), ellagic acid (476-66-4), ferullic acid (1135-246), gallic acid (149-91-7), gentisic acid (490-79-9), O-coumaric acid (583-17-5), p-coumaric acid (501-98-4), rosmarinic acid (20283-92-5), sinapic acid (530-59-6), apigenin (520-36-5), apiin-apigenin-7-(2-O-apiosylglucoside) (26544-34-3), kaempferol (520-18-3), kaempferol 3-O-D-galactoside (23627-87-4), 3-O-methylkaempferol (1592-70-7), biorobin-kaempferol 3O- $\beta$-robinobioside (17297-56-2), nicotiflorin-kaempferol 3-O$\beta$-rutinoside (17650-84-9), catechin (154-23-4), crysin-5,7dihydroxyflavone (480-40-0), chrysoeriol-3' -O-methylluteolin (491-71-4), daidzein-4,7-dihydroxyisoflavone (486-66-8), epicatechin (490-46-0), galangin (548-83-4), genistein-4',5,7-trihydroxyisoflavone (446-72-0), gossypetin-8-hydroxyquercetin (489-35-0), hesperidin (520-26-3), hesperitin (520-33-2), hispidulin-6-methoxyapigenin (1447-88-7), homoorientin-luteolin 6-C- $\beta$-D-glucoside (4261-42-1), isorhamnetin- $3^{\prime}$-methoxyquercetin (480-19-3), cacticin-isorhamnetin 3-O- $\beta$-galactoside (6743-92-6), isorhamnetin 3-O- $\beta$-D-glucoside (5041-82-7), keioside-isorhamnetin 3-O-robinobioside (107740-46-5), narcissin-isorhamnetin 3-O- $\beta$-rutinoside (604-80-8), luteolin (491-703 ), myricetin (529-44-2), naringenin (480-41-1), neohesperidin (13241-33-3), orientin-luteolin 8-C-glucoside (28608-75-5), pinocembrin (480-39-7), quercetagetin-7-O-glucoside (548-75-4), quercetin (117-39-5), hyperin-quercetin 3-O- $\beta$-galactoside (482-36-0), isoquercetrin-quercetin 3-O- $\beta$-glucoside (482-35$9)$, quercetin $3-\mathrm{O}-\beta$-gentiobioside $(7431-83-6)$, quercetin $3-\mathrm{O}$ robinobioside (52525-35-6), quercitrin-quercetin 3-Orhamnoside (522-12-3), rhamnetin (90-19-7), rutin-quercetin 3-O- $\beta$-rutinoside (153-18-4), taxifolin-dihydroquercetin (48018-2), tiliroside-kaempferol 3-O-(6" -O-p-coumaroyl) glucoside (20316-62-5), and vitexin-apigenin 8-C-glucoside (386193-4). Other standards correspond to a library made in the Phytochemistry Lab, Department of Botany, University of São Paulo.

2.2. Plant Material. Commiphora leptophloeos leaves were collected in Sumé, Paraíba, Brazil ( $7^{\circ} 40^{\prime} 08.6^{\prime \prime} \mathrm{S} 36^{\circ} 51^{\prime}$ $09.0^{\prime \prime} \mathrm{W}$ ) in July 2016. This specie was identified by Dr. Leonardo de Melo Versieux (voucher \#22.353-herbarium at Centro de Biociências from UFRN). This work was conducted under SISBIO \#56.509-1.

2.3. Leaf Extract Preparation. After harvesting, the fresh leaves were transported to the laboratory where it was washed with water to remove impurities and crushed into small pieces with the aid of scissors. Commiphora leptophloeos leaves $(100 \mathrm{~g})$ were subjected to a serial extraction with hexane $(\mathrm{EH})$, chloroform (EC), ethanol (EE), methanol (EM), and water (EAR-residual aqueous), with solvent proportion of $1: 10(w / v)(100 \mathrm{~g}$ fresh leaves to $1000 \mathrm{~mL}$ of solvent) for $24 \mathrm{~h}$ at $23^{\circ} \mathrm{C}, 150 \mathrm{rpm}$ and under light protection. Another aqueous extract (EA) was prepared according to description of traditional use $(100 \mathrm{~g}$ fresh leaves to $1000 \mathrm{~mL}$ of distilled water). All extracts were filtered on Whatman No. 1 filter paper and dried using a rotary evaporator 
(TE210, Tecnal, Piracicaba, Brazil) at $40^{\circ} \mathrm{C}$. Dried extracts were suspended in DMSO and then diluted with water to a final concentration of $10 \mathrm{mg} / \mathrm{mL}$. Samples were stored at $-20^{\circ} \mathrm{C}$ until use.

2.4. Total Phenolic Compounds. The total phenolic compounds were determined using the Folin-Ciocalteau colorimetric method $(\lambda=765 \mathrm{~nm})$ using a spectrophotometer (Biotek Epoch Microplate, California, CA, USA). Each extract $(20 \mu \mathrm{L})$ was added to a different tube containing $1.580 \mu \mathrm{L}$ of distilled water, mixed, and then it was added $100 \mu \mathrm{L}$ Folin-Ciocalteu reagent. The mixture was kept at room temperature for $10 \mathrm{~min}$., then it was added $50 \mu \mathrm{L}$ of $5 \% \mathrm{Na}_{2} \mathrm{CO}_{3}$, and it was mix in a vortex. Samples were kept for $10 \mathrm{~min}$ at room temperature and then transferred to water bath at $37^{\circ} \mathrm{C}$ for $20 \mathrm{~min}$. After this period, samples were read at $765 \mathrm{~nm}$ using a spectrophotometer (Biotek Epoch Microplate, California, CA, USA). Gallic acid (Sigma-Aldrich, Saint Louis, MO, USA) was used as a standard, and values were given per g of extract according to Athukorala et al. [9].

2.5. Thin Layer Chromatography (TLC). All samples were subjected to the following: three mobile phases using glass plates with silica gel $F_{254}$ (Merck, Germany): (1) ethyl acetate:formic acid:methanol: water (10:0.5:0.6:0.2 $\mathrm{v} / \mathrm{v} / \mathrm{v} / \mathrm{v})$; (2) toluene:methanol:water $(9: 1: 0.1 v / v / v / v)$; (3) ethyl acetate : formic acid: water $(8: 1: 1 v / v / v)$. It was used $0.1 \mathrm{~mL}$ from each extract to have a quality TLC. The development reagents used were sulphuric vanillin $(0.5 \mathrm{~g}$ vanillin, $2 \mathrm{~mL}$ $\left.\mathrm{H}_{2} \mathrm{SO}_{4}, 80 \mathrm{~mL} \mathrm{MeOH}\right)$, ferric chloride $\left(1 \mathrm{~g} \mathrm{FeCl}_{3}, 100 \mathrm{~mL}\right.$ $\mathrm{MeOH})$, natural reagent A $(0.2 \mathrm{~g}$ Difenilborato, $100 \mathrm{~mL}$ $\mathrm{MeOH}$ ), and Dragendorff's reagent (A solution: $0.85 \mathrm{~g}$ bismuth subnitrate, $10 \mathrm{~mL} \mathrm{CH}_{3} \mathrm{COOH}, 40 \mathrm{~mL}$ distilled water; solução B: $16 \mathrm{~g}$ de KI, $40 \mathrm{~mL}$ distilled water). Chromatoplates were visualised under UV light at $365 \mathrm{~nm}$. The colour and the retention factor $(r f)$ from the spots were compared to standards (coumarin, luteolin, ellagic acid, quercetin, kaempferol, catechin, isoorientin, caffeic acid, chlorogenic acid, ursolic acid, and gallic acid) (Sigma-Aldrich, Saint Louis, MO, USA) [10].

2.6. Ultrahigh Performance Liquid Chromatography with Diode Array Detector (UHPLC-DAD). Aliquots of $2 \mu \mathrm{L}$ of the six extracts (EH, EC, EE, EM, EAR, and EA) were filtered using a $0.22 \mu \mathrm{m}$ membrane (Merck) and was injected in UHPLC (Shimadzu/Prominence UFLC-XR ${ }^{\circledR}$ ) equipped with a binary analytical pump (LC-20ADXR), automatic injector (SIL-20ACXR), a photodiode array detector (SPD-M20A), and a system controlled by LC Solution ${ }^{\circledR}$ software. The column used was Poroshell 120 EC-C18 $(50 \mathrm{~mm} \times 4.6 \mathrm{~mm}$ i.d., $2.7 \mu \mathrm{m}$ ). The mobile phase (flow $0.5 \mathrm{~mL} / \mathrm{min}$ ) was a gradient of $0.1 \%$ formic acid (A) and acetonitrile: $0.1 \%$ formic acid (B). The following gradient (35 min as the total time of analysis) was applied: $0 \mathrm{~min}(99 \% \mathrm{~A}$ and $1 \% \mathrm{~B}), 3 \mathrm{~min}(91 \%$ $\mathrm{A}$ and $9 \% \mathrm{~B}), 19 \min (52 \% \mathrm{~A}$ and $48 \% \mathrm{~B}), 23 \mathrm{~min}(5 \% \mathrm{~A}$ and $95 \% \mathrm{~B}), 24 \mathrm{~min}(99 \% \mathrm{~A}$ and $1 \% \mathrm{~B})$, and $30 \mathrm{~min}$ (99\% A and $1 \% \mathrm{~B})$. The phenolic compounds were identified in the $\mathrm{UV}$-visible (360 $\mathrm{nm}$ ), and the retention time was compared with the standards: rutin, quercetin, pyrogallol, kaempferol, and gallic acid (Sigma-Aldrich, Saint Louis, MO, USA).
2.7. Ethanol Extract Analysis Using HPLC-DAD. According to our biological results, the ethanol extract (EE) profile was determined using the Agilent 1260 chromatograph with DAD detector used. Phenylpropanoid analysis was performed using a C18 column $(4.6 \mathrm{~mm} \times 150 \mathrm{~mm})$ with $3.5 \mu \mathrm{m}$ diameter particle (Zorbax Eclipse Plus C18). The extract was diluted with methanol to a concentration of $1 \mathrm{mg} / \mathrm{mL}$. The injection volume was $3 \mu \mathrm{L}$. The flow rate used in the column was $1 \mathrm{~mL} / \mathrm{min}$. The EE was analysed at a concentration of $1 \mathrm{mg} / \mathrm{mL}$. The mobile phase used was an elution gradient containing $0.1 \%$ acetic acid (A) and acetonitrile (B), and the gradient composition was $10 \%$ B (0-6 min), 10-15\% B (6-7 min), 15\% B (7-22 min), 15-50\% B (22-32 min), $50-100 \% \mathrm{~B}$ (32-42 $\mathrm{min})$, and $100 \% \mathrm{~B}$ (42-50 min). The column temperature was $45^{\circ} \mathrm{C}$, and detection was done at $352 \mathrm{~nm}$. The identification of phenolic compounds was obtained by comparison of retention time and UV-visible absorption spectra with standards of this substance.

2.8. Bioinformatics Analysis. Based on the possible bioactive molecules identified by UHPLC-DAD and HPLC-DAD analysis - rutin, vitexin, and quercetin diglycosides-the Traditional Chinese Medicine System Pharmacology (TCMSP) database was used [11]. The data obtained at TCMSP were used at Kyoto Encyclopedia Genes and Genome (KEGG database) [12]. Then, the pathways were listed in descending order according to $p$ value. These data were used to build a network using String 10 version 11 (https://string-db.org/).

\subsection{In Vitro Antioxidant Activity}

2.9.1. Reducing Power Assay. The reducing power of C. leptophloeos extracts was quantified by the reduction of potassium ferricyanide into potassium ferrocyanide $[9,13]$. The reaction mixture $(4 \mathrm{~mL})$ containing the plant extracts at 50 , 100 , and $250 \mu \mathrm{g} / \mathrm{mL}$ in phosphate buffer $(0.2 \mathrm{M}, \mathrm{pH} 6.6)$ was incubated with potassium ferricyanide $(1 \% \mathrm{w} / \mathrm{v})$ at $50^{\circ} \mathrm{C}$ for $20 \mathrm{~min}$. The reaction was terminated by the addition of $10 \%$ trichloroacetic (TCA) solution, distilled water, and $0.1 \%$ ferric chloride. The absorbance was measured at $700 \mathrm{~nm}$, using phosphate buffer as a blank. Results were expressed as activity percentage reported by $100 \mu \mathrm{g} / \mathrm{mL}$ of ascorbic acid (standard-Sigma-Aldrich, Saint Louis, MO, USA) according to Athukorala, et al. [9] and Wang et al. [13].

2.9.2. DPPH Radical Sequestration Assay. The DPPH assay was performed according to the method by Shimada et al. [14], using a 96-well plate. Aliquots of extracts (1, 2, and $5 \mu \mathrm{L})$ at final concentration of 50,100 , and $250 \mu \mathrm{g} / \mathrm{mL}$ were added, and $150 \mu \mathrm{M}$ DPPH were added into each well, mixed, and the plate kept at room temperature for $30 \mathrm{~min}$. The absorbance was measured at $517 \mathrm{~nm}$. The DPPH freeradical scavenging activity was calculated as follows:

DPPH scavenging activity : $(\%)=[1-(\mathrm{A} 1 / \mathrm{A} 0)] \times 100$, where A0 is the absorbance of the control (DPPH) and A1 is the absorbance of the samples.

2.9.3. Superoxide Radical Scavenging Activity Assay. This assay was based on the method by Dasgupta and De [15] inside a dissipating chamber of light. This assay was based on the extracts to inhibit the reduction of nitroblue 
tetrazolium (NBT) in the riboflavin-light-NBT system. The extracts at different final concentrations (100, 250, and $500 \mu \mathrm{g} / \mathrm{mL}$ ) were mixed to $3 \mathrm{~mL}$ reaction mixture $(50 \mathrm{mM}$ phosphate buffer ( $\mathrm{pH} 7.8$ ), $13 \mathrm{mM}$ methionine, $2 \mathrm{mM}$ riboflavin, $100 \mathrm{mM}$ EDTA, and $75 \mathrm{mM} \mathrm{NBT}$ ) and exposed to a fluorescent lamp for $10 \mathrm{~min}$. Thereafter, absorption was measured at $560 \mathrm{~nm}$-EDTA was used as a control and distilled water as the blank. Results were expressed as percent of radical scavenging:

Percentage of radical scavenging $=([$ Acontrol Asample $] /[$ Acontrol - Ablank $]) \times 100$.

Acontrol: absorbance of the control; Asample: absorbance of the sample; Ablank: absorbance of the blank.

2.10. Cell Viability Assay. Cell viability of the murine fibroblast cell line NIH/3T3 (ATCC CRL-1658TM, Manassas, VA, USA) and B16-F10 cell lines (ATCC CRL-6475, Manassas, VA, USA) was evaluated against ethanol extract (EE). The EE was chosen due to the results obtained with in vitro antioxidant assays. Cells were grown in Dulbecco's modified Eagle's medium (DMEM) (Cultilab, São Paulo, Brazil) in $75 \mathrm{~cm}^{2}$ flasks, supplemented with fetal bovine serum (FBS) (LGC Biotecnologia, São Paulo, Brazil). Cells were seeded into 96-well plates at a density of $5 \times 10^{3}$ cells/well and allowed to attach overnight in $200 \mu \mathrm{L}$ of medium with $10 \%$ FBS (LGC Biotecnologia, São Paulo, Brazil) at $37^{\circ} \mathrm{C}$, in $5 \%$ $\mathrm{CO}_{2}$. After $24 \mathrm{~h}$, the EE was added in three different concentrations: 50,100 , and $250 \mu \mathrm{g} / \mathrm{mL}$ for a period of $24 \mathrm{~h}$ at $37^{\circ} \mathrm{C}$ and $5 \% \mathrm{CO}_{2}$. Thereafter, the medium and extract were removed and $100 \mu \mathrm{L}$ of fresh medium and $10 \mu \mathrm{L}$ of $12 \mathrm{mM}$ MTT (3-(4,5-dimethylthiazol-2-yl)-2,5-diphenyltetrazolium bromide) (Sigma-Aldrich, Saint Louis, MO, USA) dissolved in PBS were added. The plate was incubated for $4 \mathrm{~h}$ at $37^{\circ} \mathrm{C}$ in $5 \% \mathrm{CO}_{2}$. In order to solubilise the reduced MTT product, $100 \mu \mathrm{L}$ of absolute ethyl alcohol was added to each well and mixed [16]. The absorbance was measured at $570 \mathrm{~nm}$. The percentage of cell viability was calculated as:

$$
\text { Percentage of MTT reduction }=\left(\frac{\text { Abs of sample }}{\text { Abs of control }}\right) \times 100 \text {. }
$$

2.11. Caenorhabditis elegans Strains and Cultivation. The Caenorhabditis elegans strains used in this study were the N2 (wild-type) and transgenic line CF1553 (muIs84[pAD76(sod$3::$ GFP) + rol-6(su1006)]. Caenorhabditis elegans were cultivated in Nematode Growth Medium (NGM) with Escherichia coli OP50 and maintained at $20^{\circ} \mathrm{C} \mathrm{[17].} \mathrm{Synchronised} \mathrm{first} \mathrm{larval}$ stage (L1) worms were obtained by treating gravid hermaphrodites with $2 \%$ sodium hypochlorite and allowing the eggs to hatch on M9 buffer overnight. For treatment, EE was filtered using a $0.22 \mu \mathrm{m}$ filter (Merck), and subsequently, it was added to the NGM at a final concentration of either $1 \mathrm{mg} / \mathrm{mL}$ or $10 \mathrm{mg} / \mathrm{mL}$. Worms were incubated with E. coli OP50 for $48 \mathrm{~h}$.

2.12. Effect of Ethanol Extract on Caenorhabditis elegans Development. The effects of EE on egg hatching was determined. Caenorhabditis elegans eggs were incubated in plates containing NGM and E. coli OP50 in the absence or presence of $\mathrm{EE}$ at 100, 250, 500, and $1,000 \mu \mathrm{g} / \mathrm{mL}$. Approximately 50 eggs per plate were added to a total of five plates per treatment. After the incubation period, the number of hatched eggs was analysed using the following formula:

$$
\text { Hatching percentage }=\left(\frac{(\text { No.of larvae })}{(\text { No.of eggs })} \times 100\right) \text {. }
$$

The other aspect analysed was the body length. The L1 synchronised worms were kept at NGM medium plus E. coli OP50 in the absence or presence of EE at 100, 250, 500, and $1000 \mu \mathrm{g} / \mathrm{mL}$. These plates were kept at $20^{\circ} \mathrm{C}$ for $48 \mathrm{~h}$. Approximately 25 animals were used per treatment, and each experiment was performed in triplicate. The animals were photographed, and their body length was measured using Image J software, version 1.8 .

2.13. Quantification of Intracellular ROS. Wild-type animals synchronised at L1 were kept on NGM plates with E. coli OP50. These worms were treated with EE at concentrations of $0,100,500$, and $1000 \mu \mathrm{g} / \mathrm{mL}$ for $48 \mathrm{~h}$. Thereafter, worms were washed thrice with M9 buffer and incubated with $500 \mu \mathrm{L}$ M9 buffer. Afterward, approximately 40 animals were transferred to 96-well plates containing $2 \mathrm{mM} \mathrm{H} 2 \mathrm{DCF}-\mathrm{DA}$ (2,7-dichlorofluorescein diacetate fluorescent probe), to measure ROS levels. Samples were read using a multilabel microplate reader GloMax ${ }^{\circledR}$-Multi Detection System (Promega, Wisconsin, USA), with excitation at $490 \mathrm{~nm}$ and emission at $510-570 \mathrm{~nm}$, and the mean values were calculated. Readings were done intermittently every $30 \mathrm{~min}$ during $4 \mathrm{~h}$. This assay was performed in triplicate.

2.14. Survival Test under Oxidative Stress Conditions. Synchronised wild-type animal at L4 were treated with EE at concentrations of $0,100,500$, and $1000 \mu \mathrm{g} / \mathrm{mL}$ for $48 \mathrm{~h}$. Thereafter, approximately 50 animals were transferred to 24-well plates with NGM containing $10 \mathrm{mM}$ t-BOOH (tertbutyl hydroperoxide). Survival was monitored every three hours until all animals were considered dead (no movement). Each group was made up of 10 animals, and each assay was analysed five times [18].

2.15. Analysis of sod-3::GFP Expression. The transgenic line $\mathrm{CF} 1553$ worms were treated with $\mathrm{EE}$ at $0,100,500$, and $1000 \mu \mathrm{g} / \mathrm{mL}$ for $48 \mathrm{~h}$. Thereafter, 25 worms were transferred to microscopic slides with $1 \%$ agarose and covered. These worms were photographed using an Olympus BX51 fluorescence microscope using a 10-fold eye magnification and $365 \mathrm{~nm}$ excitation filter. The GFP fluorescence intensity was analysed using ImageJ Software version 1.8 (https://imagej.net).

2.16. Statistical Analysis. The results were expressed as the mean \pm standard deviations. Each assay was repeated 2-3 times and was performed in triplicate or quintuplet. Statistical analysis was performed using GraphPad Prism 6.0 (2014), and the results were obtained using one-way analysis of variance (ANOVA) followed by Tukey's post hoc analysis $(P<0.05)$ 


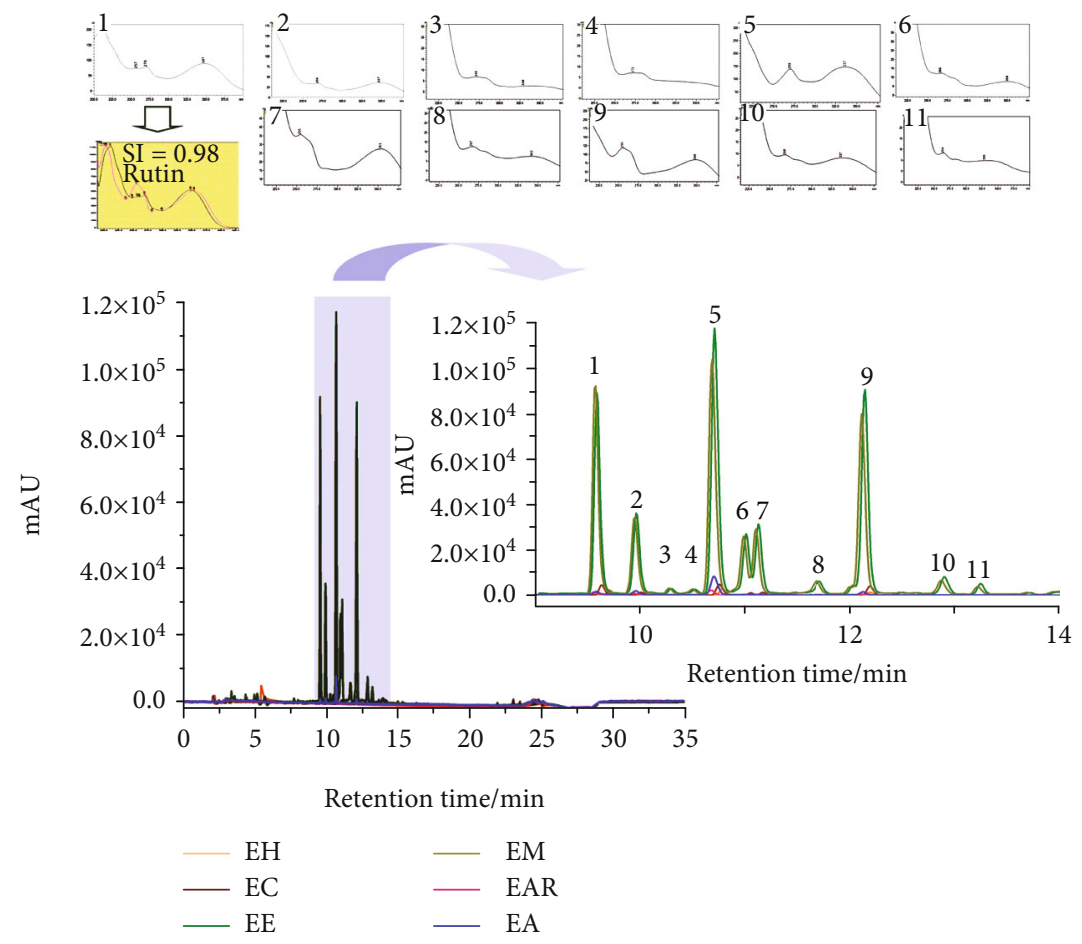

(a)

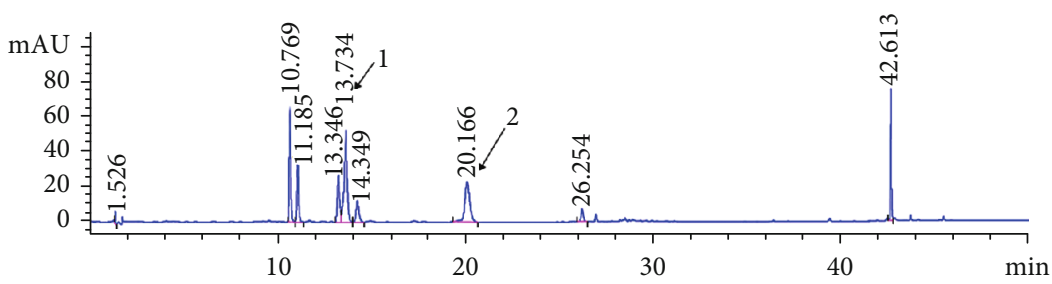

(b)

Figure 1: UHPLC chromatogram. The extracts: EH (hexane extracT), EC (chloroform extract, EE (ethanol extract), EM (methanol extract), EAR (residual aqueous extract), EA (aqueous extract) were analysed using UHPLC-DAD at $360 \mathrm{~nm}$. In (a), the chromatogram obtained for each extract is shown. Green represents the chromatogram detail obtained for the EE. Peak number 1 corresponds to rutin. The $x$-axis corresponds to the retention time ( $\mathrm{min}$ ) of each peak. The $y$-axis corresponds to the intensity of the peaks in $\mathrm{mAU}$. In (b), the EE analysis using HPLC-DAD was shown. The detection wavelength was set at $360 \mathrm{~nm}$, the $x$-axis corresponds to the retention times (min) of each peak, and the $y$-axis corresponds to the intensity of the peaks in mAU. The peak absorption spectra \#1 corresponds to vitexin \#2 to quercetin diglycosides.

\section{Results}

3.1. Commiphora leptophloeos Leaf Extracts Are Rich in Phenolic Compounds. In this study, a serial approach using solvents from different polarity (nonpolar to polar) was done in order to obtain five extracts from C. leptophloeos leaves: hexane (EH), chloroform (EC), ethanol (EE), methanol (EM), and water (EAR-residual aqueous), and the sixth extract was prepared only with water-EA. The total phenolic content of compounds obtained ranged from $5.44 \pm 0.4 \mathrm{mg} / \mathrm{g}$ to 126.41 $\pm 1.8 \mathrm{mg} / \mathrm{g}$. The $\mathrm{EH}$ had $10.18 \pm 0.4 \mathrm{mg} / \mathrm{g}$, while EC had $42.47 \pm 0.2 \mathrm{mg} / \mathrm{g}$, EAR had $24.27 \pm 0.6 \mathrm{mg} / \mathrm{g}$, and EA had $5.44 \pm 0.4 \mathrm{mg} / \mathrm{g}$. The highest values were obtained from the EM $(126.41 \pm 1.8 \mathrm{mg} / \mathrm{g})$ and $\mathrm{EE}(105.67 \pm 1.7 \mathrm{mg} / \mathrm{g})$.

The presence of terpenes was observed in TLC analysis for the EH. The presence of terpenes, phenolic acids, and fla- vonoids was detected in the EC; terpenes, phenolic compounds, flavonoids, saponins, and tannins were observed in both the EE and EM. Phenolic compounds were detected for EAR and not observed for EA. Moreover, the fingerprinting analysis of extracts via UHPLC-DAD allowed the detection of several compounds similar to phenols at higher concentrations mainly in EE and EM according to UV spectra (see Figure 1(a)). In green represented the EE, and the peak \#1 may correspond to the rutin flavonoid $(\operatorname{tr}=9.6)$. Regrettably, the other peaks in Figure 1(a) may not be determined by our analysis.

Based on the biological results obtained with EE, then it was analysed using HPLC-DAD at $360 \mathrm{~nm}$. The presence of vitexin-peak $1(\operatorname{tr}=13,734)$; peak 2$)$, and peak 2 suggested the presence of quercetin diglycosides $(\mathrm{tr}=20,166)$ (see Figure 1(b)). 
TABLe 1: Data obtained from KEGG using the rutin, vitexin, and quercetin diglycosides as target after the overlap analysis.

\begin{tabular}{lccc}
\hline KEGG Brite (Homo sapiens) & Adjusted $p$ value & Corrected $p$ value & Related genes (targets) \\
\hline Immune system & $6.61 e-19$ & $1.22 e-16$ & PTGS2; CASP3; CXCL8; IL6; TNF; MAPK7; HSP90AA1; IL1B; \\
Cardiovascular disease & $7.83 e-09$ & $7.62 e-08$ & RELA \\
Infectious disease bacterial & $2.27 e-12$ & $1.05 e-10$ & REA; HSP90AA1; IL1B; TNF; MAPK7; IL6; CXCL8; \\
Infectious disease viral & $4.03 e-10$ & $6.77 e-09$ & PRSS1; CASP3; CXCL8; IL6; TNF; IL1B; RELA; PTGS2; PIK3CG \\
Infectious disease parasitic & $1.83 e-09$ & $2.37 e-08$ & IL6; CXCL8; IL1B; TNF; RELA \\
Neurodegenerative disease & $8.18 e-07$ & $4.32 e-06$ & IL6; IL1B; SOD1; TNF; CASP3 \\
Pathways in cancer & $5.16 e-09$ & $5.30 e-08$ & PTGS2; CASP3; CXCL8; IL6; PPARG; HSP90AA1; RELA \\
Nervous system & $2.52 e-05$ & $8.48 e-05$ & PTGS2; PTGS1; CASP3 \\
Metabolic pathways & $1.42 e-08$ & $1.19 e-07$ & PTGS2; PTGS1; PIK3CG; AR; ETNK2; ETNK1; CAT; CHKA; \\
Lipid metabolism & $1.65 e-07$ & $1.05 e-06$ & CHKB \\
$\begin{array}{l}\text { Development and regeneration } \\
\text { Cell growth and death }\end{array}$ & $4.8 e-07$ & $2.71 e-06$ & ETNK1; CHKA; CHKB; ETNK2 \\
Transcription misregulation in & $4.11 e-05$ & 0.000135 & PPARG; IL1B; TNF; RELA \\
cancer & $2.07 e-06$ & $1.00 e-05$ & RELA; TNF; CASP3; IL6; CXCL8; RELA; HSP90AA1; IL1B \\
Cancer & $1.36 e-05$ & $5.24 e-05$ & IL6; CXCL8; RELA; PPARG
\end{tabular}

3.2. Bioinformatics Analysis. Bioinformatics may be a powerful tool to make a data mining from potential targets using the bioactive molecules presented in the extracts. The pharmacological analysis was done in order to identify the potential targets from the three bioactive molecules presens at C. leptophloeos leaf extract: rutin, vitexin, and quercetin diglycosides. It may be observed that these molecules may be associated to pathways that were related to anti-inflammatory, cardiovascular disease, neurodegenerative disease, cancer, and others. It was observed more than 56 targets (see Table 1). Moreover, when the overlap was analysed, then some gene argets were PTGS2, PIK3CG, CASP3, MAPK7, SOD, CAT, ETNK1, ENTK2, HSP90, TNF, IL1 $\beta$, and IL6 (see Table 1, Figure 2) Furthermore, the bioinformatics approach proposed that the bioactive molecules identified at $C$. leptophloeos may have an antioxidant activity.

In Figure 2, it may be observed how the genes identified at Table 1 may interact. Although many of these genes are correlated to the immune system, there is also a correlation to oxidative stress as the SOD2 (Sodium Dismutase) and CAT (Catalase) was observed for example. Then, this approach showed that it was important to analyse if these extracts (complex mixture of bioactive molecules) may have antioxidant activities and others activities.

3.3. In Vitro Antioxidant Assays and In Vivo Cell Viability. Considering the presence of phenolic compounds in the order $\mathrm{EM}>\mathrm{EE}>\mathrm{CE}>\mathrm{EAR}>\mathrm{EH}>\mathrm{EA}$, the in vitro antioxidant capacity of these extracts were then evaluated using seven different assays. The extract concentrations that were analysed were 50,100 , and $250 \mu \mathrm{g} / \mathrm{mL}$. The assays that had activity were presented. The reducing power potential increased in a dose-dependent manner (see Figure 3(a)). A $100 \%$ reducing power potential was observed at $250 \mu \mathrm{g} / \mathrm{mL}$ for both EE and EM (see Figure 3(a)). The DPPH assay

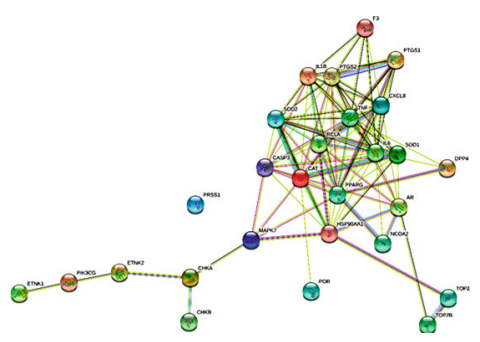

Figure 2: Gene network from Commiphora leptophloeos bioactive molecules. The data obtained from KEEG were used to build a network using SRTING10 version 11. Each circle corresponds to a gene; the lines are how these genes are connected between each other. The blue line corresponds to curate database; pink determined experimentally; yellow data from text mining; black coexpression; green colour means gene neighbourhood.

displayed saturation as the value reached $100 \%$ of DPPH scavenging at the lowest concentration $(50 \mu \mathrm{g} / \mathrm{mL})$ (see Figure 3(b)). Moreover, the EE and EM exhibited the highest superoxide radical scavenging potential (see Figure 3(c)). The EE reached $65 \%$ at $100 \mu \mathrm{g} / \mathrm{mL}$.

Since EE presented the highest antioxidant activity amongst all extracts, its effect on NIH/3T3 cell viability was analysed (see Figure 3(d)). As expected, no effect on cell viability was observed. Furthermore, higher concentrations of EE seemed to increase cell metabolism and viability when measured by the MTT assay (see Figure 3(d)). On the other hand, when it was evaluated, the EE effect on B16F10 tumour cell line was observed a cytotoxicity effect as it may be observed a reduction on cell viability in a range of $30 \%$ at $100 \mu \mathrm{g} / \mathrm{mL}$ up to $45 \%$ at $500 \mu \mathrm{g} / \mathrm{mL}$ extract concentration.

3.4. Effect of Commiphora leptophloeos EE on Caenorhabditis elegans Development. The nematode C. elegans was used to 


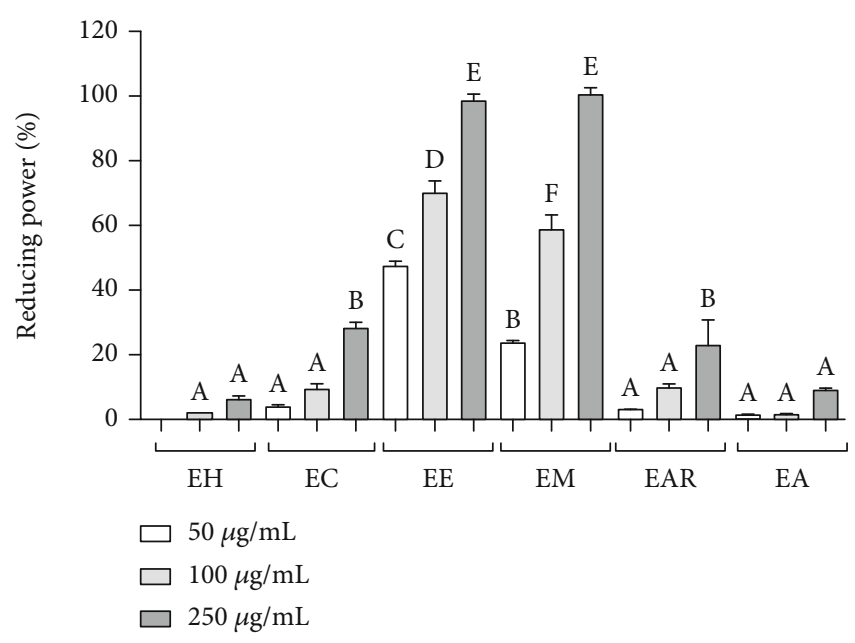

(a)

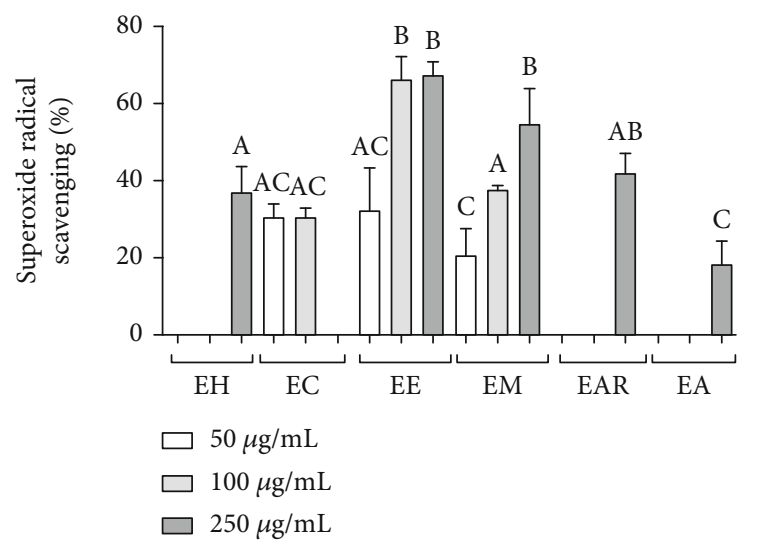

(c)

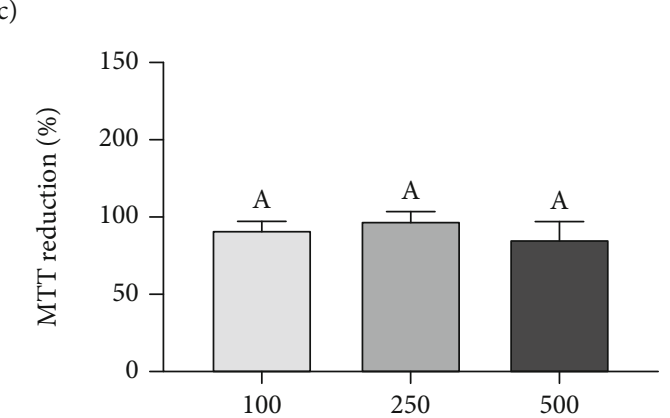

(e)

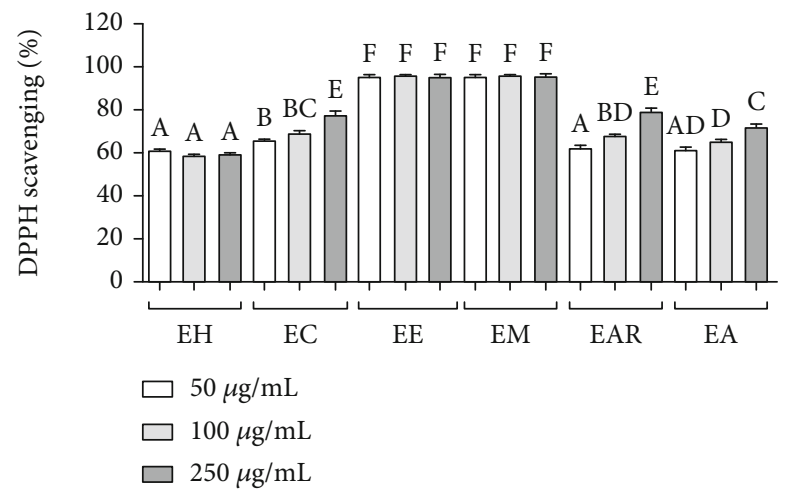

(b)

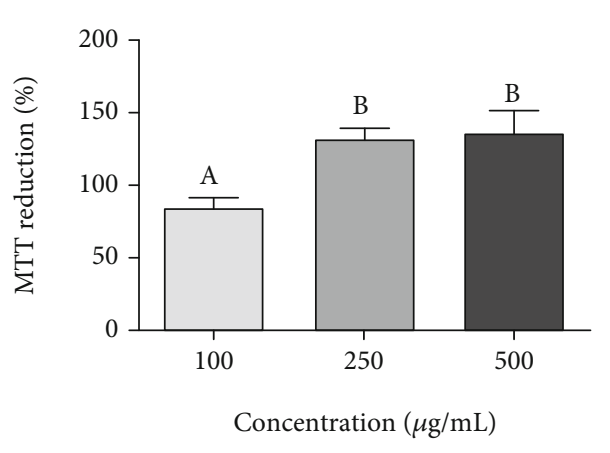

(d)

FIGURE 3: Antioxidant activity assays and cell viability assay. The antioxidant assays were performed using the Commiphora leptophloeos extract concentration at 50,100, and $250 \mu \mathrm{g} / \mathrm{mL}$. (a) Reducing power assay. The $x$-axis corresponds to the different extracts and concentrations used. The $y$-axis corresponds to the activity percentage, based on the standard curve using ascorbic acid as a standard. (b) DPPH assay. The $x$-axis corresponds to the different extracts and concentration. The $y$-axis corresponds to the DPPH percentage scavenging. (c) Superoxide radical scavenging assay. The $x$-axis corresponds to the different C. leptophloeos extracts. The $y$-axis corresponds to the percentage scavenging. (d) Cell viability of the NHI/3T3 cell line after $24 \mathrm{~h}$ of ethanol extract (EE) treatment. The $x$ -axis corresponds to EE concentration at $100 \mu \mathrm{g} / \mathrm{mL}, 250 \mu \mathrm{g} / \mathrm{mL}$, and $500 \mu \mathrm{g} / \mathrm{mL}$. The $y$-axis corresponds to the percentage of cell viability via MTT reduction. (e) Cell viability of the B16F10 tumour cell line after $24 \mathrm{~h}$ of EE treatment. The $x$-axis corresponds to EE concentration at $100 \mu \mathrm{g} / \mathrm{mL}, 250 \mu \mathrm{g} / \mathrm{mL}$, and $500 \mu \mathrm{g} / \mathrm{mL}$. The $y$-axis corresponds to the cell viability percentage via MTT reduction. EH: hexane extract; EC: chloroform extract; EE: ethanol extract; EM: methanol extract; EAR: residual aqueous extract; EA: aqueous extract. All assays (a-e) were done in triplicate for each extract, and the data obtained were analysed using ANOVA and Tukey's test $(P \leq 0.05)$. Different letters (a, b, c, d, e, and f) correspond to significant differences. 


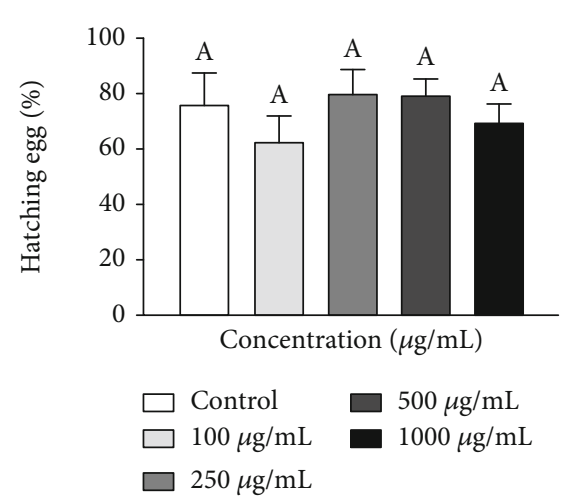

(a)

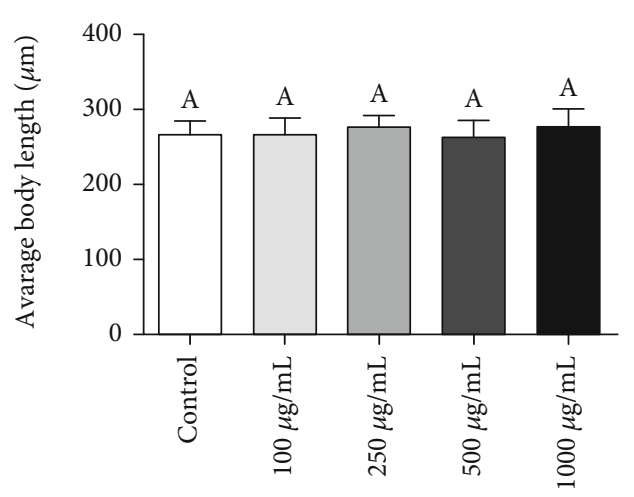

(b)

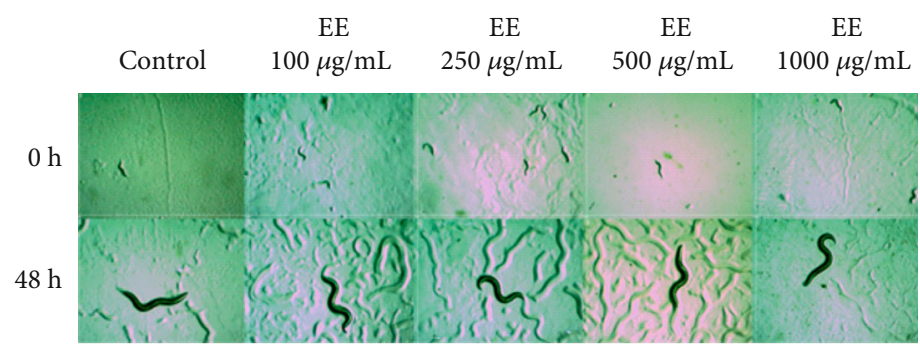

(c)

FIGURE 4: Ethanol extract (EE) effect on Caenorhabditis elegans wild-type growth and development. Wild-type C. elegans animals were treated with EE at $0,100,250,500$, and $1000 \mu \mathrm{g} / \mathrm{mL}$ concentration. (a) Egg hatching assay. The $x$-axis corresponds to concentrations of EE. The $y$-axis corresponds to the percentage of egg hatching. (b) Body length was measured using Image J software. The $x$-axis corresponds to EE concentrations used. The $y$-axis corresponds to body length. (c) Image from the animal at $0 \mathrm{~h}$ and $48 \mathrm{~h}$ of EE treatment at the different concentrations. Three independent experiments were performed, with three replicates per treatment (A-B-C). The data were analysed by ANOVA and Tukey's test $(P \leq 0.05)$.

analyse the EE effect on animal development as well as its antioxidant capacity using this in vivo model. The EE concentration used were $0,100,250,500$, and $1000 \mu \mathrm{g} / \mathrm{mL}$. The $1000 \mu \mathrm{g} / \mathrm{mL}$ concentration was used due to the C. elegans cuticle. The effect of EE on the development $C$. elegans was evaluated, and any effects on egg hatching at any of the concentrations analysed were not observed (see Figure 4(a)). Moreover, any modifications in body length (see Figure 4(b)) nor in animal development (see Figure 4(c)) were not observed.

3.5. In Vivo Antioxidant Effect of EEs Using Caenorhabditis elegans. Since EE exhibited an in vitro antioxidant capacity and had any cytotoxic effects on cell viability and on C. elegans development, it was essential to evaluate the effect of EE treatment on ROS production using the C. elegans model. The EE treatment at 500 and $1000 \mu \mathrm{g} / \mathrm{mL}$ was able to reduce approximately $50 \%$ of the intracellular ROS level when compared to the untreated control (see Figure 5(a)). Furthermore, it was also observed that the EE concentration of $1000 \mu \mathrm{g} / \mathrm{mL}$ increased survival under oxidative stress induced by $\mathrm{t}-\mathrm{BOOH}$ (see Figure 5(b)). The mean survival time of $1000 \mu \mathrm{g} / \mathrm{mL}$ of EEtreated animals increased by $5 \%$ compared to the untreated control. Moreover, it was observed that the expression level of sod-3::GFP transgenic animals was reduced by approximately $50 \%$ on GFP expression, when treated with any EE concentration (see Figures 5(c) and 5(d)).

\section{Discussion}

Over the years, medicinal plants have received growing attention in research for the identification and characterization of new intermediate metabolites that may have a different biological effect [4]. Illnesses like cancer, diabetes, cardiovascular disease, inflammatory disease, aging, Parkinson's disease, and Alzheimer's disease have been associated with oxidative stress. The antioxidant effect of plant intermediate metabolites have an important impact on the maintenance of cellular redox homeostasis and could potentially influence the mechanism of these diseases [5, 19-23].

Commiphora leptophloeos is used in folk medicine for gastritis, anti-inflammatory, asthma, and bronchitis [24, 25] but no scientific information. The data in this study showed that all the extracts displayed antioxidant activity at in the $\mathrm{DPPH}$ assay. Considering that the antioxidant activity has three steps: initiation, propagation, and termination [2628]; our data showed that the EE and EM had activity at the initiation (DPPH and reducing power) and termination phase (superoxide radical scavenging).

Pereira et al. [8] worked with Commiphora leptophloeos stem bark, and they also identified the presence of phenolic compounds, flavonoids, and sugars. Our TLC, UHPLC, and HPLC data showed the presence of phenolic compounds such as rutin, vitexin, and possible quercetin diglycosides, especially in EE C. leptophloeos. The bioinformatics analysis 


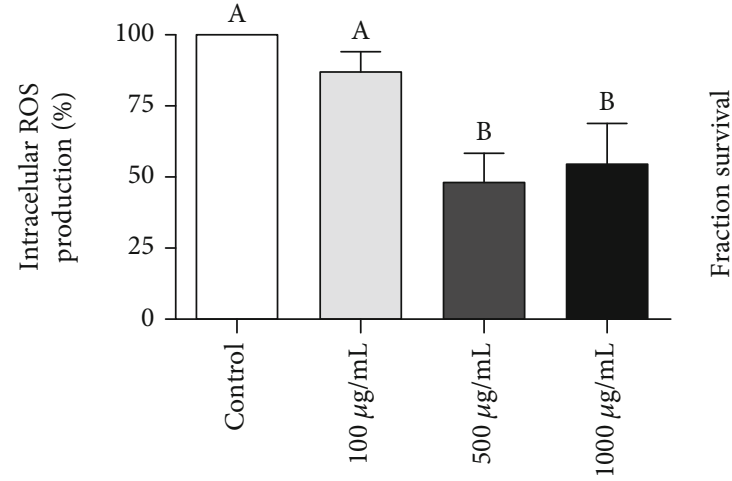

(a)

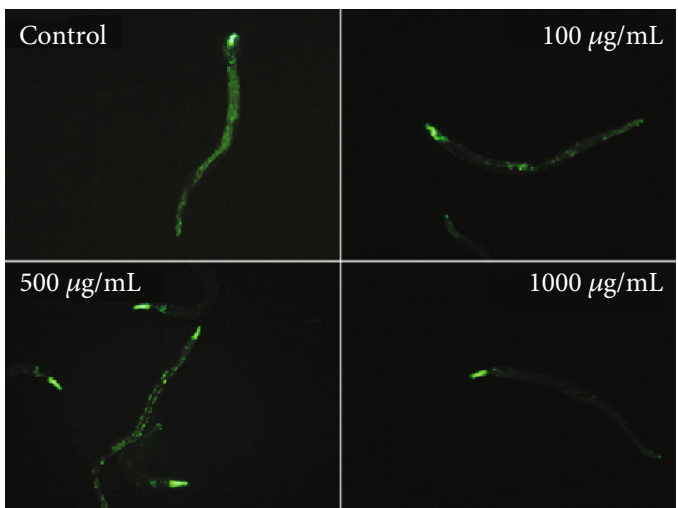

(c)

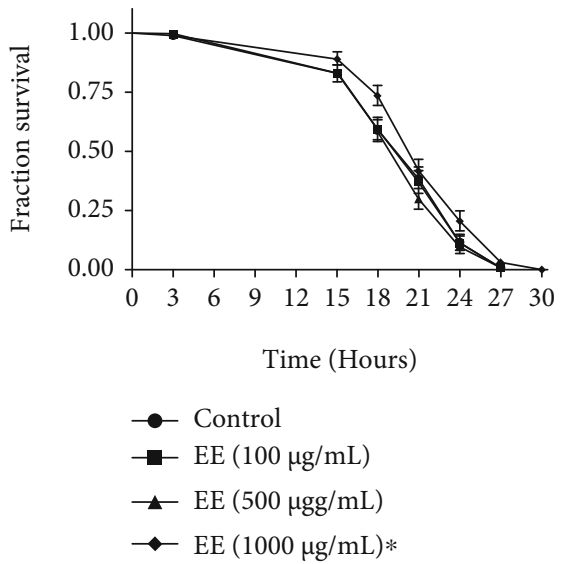

(b)

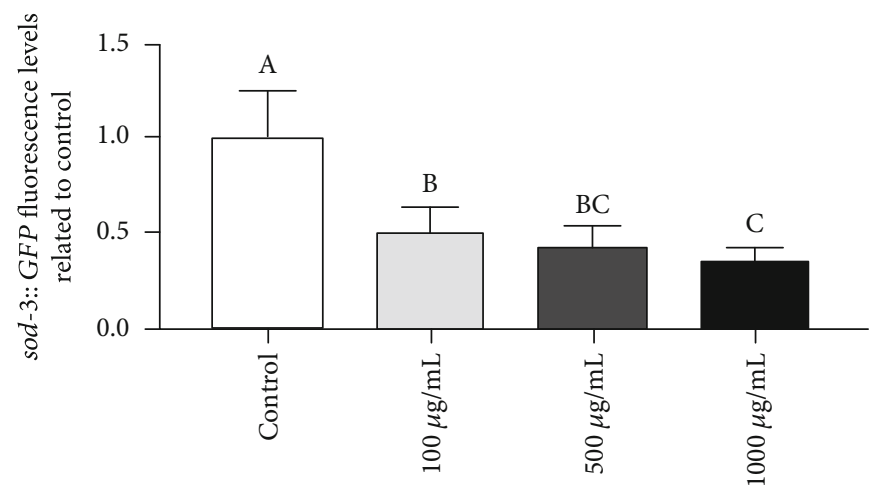

(d)

FIGURE 5: Ethanol extract (EE) antioxidant effect on Caenorhabditis elegans model. (a) Levels of reactive oxygen species (ROS) in N2 wildtype animals treated with the C. leptophloeos EE for $48 \mathrm{~h}$. (b) Survival assay of N2 wild-type animals under oxidative stress conditions with $\mathrm{t}$-BOOH. Animals were treated with $0,100,500$, or $1000 \mu \mathrm{g} / \mathrm{mL}$ of EE at L1 to L4. The $x$-axis corresponds to the hours observed (3 to $30 \mathrm{~h}$ ), and the $y$-axis, to the survival fraction. Three independent experiments were performed, with three replicates per treatment. The EE treatment was compared to the control by the Log-rank test $(P<0.0001)$. (c) sod-3::GFP expression in $C$. elegans after EE treatment 0 , 100,500 , or $1000 \mu \mathrm{g} / \mathrm{mL}$. The images were taken using the Olympus BX51 microscope. (d) sod-3::GFP expression was quantified. The $x$ -axis corresponds to different concentrations of C. leptophloeos EE. The $y$-axis corresponds to GFP expression quantification. For all assays, three independent experiments were performed, with three replicates per treatment. Different letters correspond to significant differences. Statistical analysis was performed using ANOVA and Tukey test $(P \leq 0.05)$.

associated to the phenolic compounds identified possible gene targets that were associated to antioxidant and antiinflammatory pathways. It has been observed that misbalance between ROS production and degradation may produce an oxidative stress, which may be associated to inflammatory process as well as to different diseases [19]. Moreover, it has been shown that phenolic compounds as rutin, quercetin, and others may acts in signalling pathways involved in the inflammatory process [19]. Soukhtanloo et al. [22] showed that NF-kb signalling pathway may be a target for some natural products. Choudhari et al. [5] also showed the use of phytochemicals were promising at preclinical treatments. Moreover, He et al. [29] showed that vitexin and isovitexin, active phytochemicals in medicinal plants, have a broad spectrum effect including antioxidant, antiproliferative, antiinflammatory, and antihyperalgesic effects $[29,30]$. Furthermore, a neuroprotective effect that increases viability and impacts LDH release was observed. This could potentially influence Alzheimer's disease due to its neurological protection. The results showed the presence of rutin and probably the presence of quercetin diglycosides in $\mathrm{EE} \mathrm{C}$. leptophloeos extracts. These flavonoids showed promising antioxidant, anti-inflammatory, and immunoprotective activities and may be used to treat cardiovascular diseases, diabetes, asthma, and cancer $[6,31,32]$. The other flavonoid identified in C. eptophloeos extracts was rutin. It is commonly found in dark-coloured fruits that are known to have antioxidant, anti-inflammatory, neuroprotective, and other biological activities [33]. Furthermore, the chemical composition of C. leptophloeos is similar to other species from the genus $[34,35]$.

The evaluation of cell toxicity is an important step in the discovery and application of new drugs. Thus, the data of cell lines and the $C$. elegans model showed that the EE had no in vivo cytotoxic effects on the NIH/3T3 cell line, only for B16F10 tumour cell line. Moreover, EE did not affect C. elegans egg hatching, body length, and development, which are 
all important parameters for toxicity $[36,37]$. Literature, it showed that the flavonoids identified did not affect cell viability. However, as plant extracts contain a mixture of phytocompounds, it was important to analyse this aspect using cell lines and the C. elegans model $[4,38,39]$.

Furthermore, C. elegans data reinforce the outcome of the bioinformatics and in vitro antioxidant assays as it verified that EE have the potential to reduce ROS production, even when animals were treated with $\mathrm{t}-\mathrm{BOOH}$ (oxidative agent). Moreover, during oxidative stress, excessive production of ROS may promote lesions on DNA as well as promote cell damage. The compounds present in extracts reduced or neutralised ROS effects; thus, they are important for redox homeostasis [29, 32]. Kampkotter et al. [40] showed that treatment with $100 \mu \mathrm{M}$ of rutin reduced ROS levels by $15 \%$ in C. elegans. The data presented here also showed an effect on life span after EE treatment in animals that have been associated with the antioxidant capacity.

In this study, a reduction of sod-3::GFP expression (reporter gene) was observed in animals treated with EE. This reduction may be associated with the ROS scavenging effect of EE. Similar results were also observed when animals were treated with quercetin or Anacardium occidentale extracts $[41,42]$. The data suggest that these extracts may act synergistically with phenolic compounds to protect cells and $C$. elegans from oxidative stress by assisting in ROS reduction, consequently helping to maintain cellular homeostasis [28, $38,39,42-44]$.

\section{Conclusions}

The results presented here showed the antioxidant capacity of C. leptophloeos leaf extracts, especially for ethanol extract (EE). Our data showed the presence of phenolic compounds (rutin, vitexin, and quercetin diglycosides, amongst others), and no cytotoxic effects were observed on cell viability and C. elegans. Furthermore, potential antioxidant activity was observed using bioinformatics, in vitro and in vivo assays. The intermediate metabolites observed in ethanol extract (EE) may potentially reduce ROS effects and consequently maintain redox homeostasis. Thus, Commiphora leptophloeos is a promising plant species for future studies on biological activity as oxidative stress is involved in different chronic diseases.

\section{Data Availability}

The data obtained in this study are available from the corresponding author upon request.

\section{Conflicts of Interest}

The authors have no conflicts of interest to declare.

\section{Acknowledgments}

The authors wish to thank Conselho Nacional de Desenvolvimento Científico e Tecnológico-CNPq, Coordenação de Aperfeiçoamento Pessoal de Nível Superior-CAPES, and Ministério de Ciência, Tecnologia, Inovação e Comércio
(MCTIC) for the financial support. H.A.O. R. is a CNPq fellowship honored researcher. M.L.S.C., A.R.C.R., L.F.M.M., G.P.F., L.M.P.S., R.B.O.C., and C.O.M.C. received a scholarship from CAPES.

\section{References}

[1] M. Fridlender, Y. Kapulnik, and H. Koltai, "Plant derived substances with anti-cancer activity: from folklore to practice," Frontiers in Plant Science, vol. 6, pp. 1-9, 2015.

[2] H. Khan, H. Ullah, P. C. M. F. Castilho et al., "Targeting NF- $\kappa$ B signaling pathway in cancer by dietary polyphenols," Critical Reviews in Food Science and Nutrition, vol. 60, no. 16, pp. 2790-2800, 2020.

[3] D. J. Newman and G. M. Cragg, "Natural products as sources of new drugs from 1981 to 2014," Journal of Natural Products, vol. 79, no. 3, pp. 629-661, 2016.

[4] B. Armendáriz-Barragán, N. Zafar, W. Badri et al., "Plant extracts: from encapsulation to application," Expert Opinion on Drug Delivery, vol. 13, no. 8, pp. 1165-1175, 2016.

[5] A. S. Choudhari, P. C. Mandave, M. Deshpande, P. Ranjekar, and O. Prakash, "Phytochemicals in cancer treatment: from preclinical studies to clinical practice," Frontiers in Pharmacology, vol. 10, pp. 1-17, 2020.

[6] D. M. Kasote, S. S. Katyare, M. V. Hegde, and H. Bae, "Significance of antioxidant potential of plants and its relevance to therapeutic applications," International Journal of Biological Sciences, vol. 11, no. 8, pp. 982-991, 2015.

[7] A. Singh, R. Kukreti, L. Saso, and S. Kukreti, "Oxidative stress: a key modulator in neurodegenerative diseases," Molecules, vol. 24, no. 8, p. 1583, 2019.

[8] J. J. de Souza Pereira, A. . P. C. Pereira, J. J. B. Jandú et al., "Commiphora leptophloeos phytochemical and antimicrobial characterization," Frontiers Microbiology, vol. 8, no. 52, pp. 1-10, 2017.

[9] Y. Athukorala, K. N. Kim, and Y. J. Jeon, “Antiproliferative and antioxidant properties of an enzymatic hydrolysate from brown alga,_Ecklonia cava_," Food and Chemical Toxicology, vol. 44, no. 7, pp. 1065-1074, 2006.

[10] H. Wagner and S. Bladt, Plant Drug Analysis: A Thin Layer Chromatography Atlas, Springer, Berlin, Germany, 2nd ed. edition, 2001.

[11] J. Ru, P. Li, J. Wang et al., "TCMSP: a database of systems pharmacology for drug discovery from herbal medicines," Journal of Cheminformatics, vol. 6, no. 1, pp. 1-6, 2014.

[12] M. Kanehisa, M. Furumichi, M. Tanabe, Y. Sato, and K. Morishima, "KEGG: new perspectives on genomes, pathways, diseases and drugs," Nucleic Acids Research, vol. 45, no. D1, pp. D353-D361, 2017.

[13] J. Wang, Q. Zhang, Z. Zhang, and Z. Li, "Antioxidant activity of sulfated polysaccharide fractions extracted from _Laminaria japonica_," International Journal of Biological Macromolecules, vol. 42, no. 2, pp. 127-132, 2008.

[14] K. Shimada, K. Fujikawa, K. Yahara, and T. Nakamura, “Antioxidative properties of xanthan on the autoxidation of soybean oil in cyclodextrin emulsion," Journal of Agricultural and Food Chemistry, vol. 40, no. 6, pp. 945-948, 1992.

[15] N. Dasgupta and B. De, “Antioxidant activity of _Piper betle_ L. leaf extract in vitro," Food Chemistry, vol. 88, no. 2, pp. 219$224,2004$. 
[16] T. Mosmann, "Rapid colorimetric assay for cellular growth and survival: application to proliferation and cytotoxicity assays," Journal of Immunological Methods, vol. 65, no. 1-2, pp. 55-63, 1983.

[17] S. Brenner, "The genetics of Caenorhabditis elegans," Genetics, vol. 77, no. 1, pp. 71-94, 1974.

[18] A. R. C. Ribeiro, M. L. S. Cordeiro, L. M. P. Silva et al., "Myrciaria tenella (DC.) O. Berg (Myrtaceae) leaves as a source of antioxidant compounds," Antioxidants, vol. 8, no. 8, pp. 310-314, 2019.

[19] T. Hussain, B. Tan, Y. Yin, F. Blachier, M. C. B. Tossou, and N. Rahu, "Oxidative stress and inflammation: what polyphenols can do for us?," Oxidative Medicine and Cellular Longevity, vol. 2016, 9 pages, 2016.

[20] E. B. Lee, M. M. Xing, and D. K. Kim, "Lifespan-extending and stress resistance properties of brazilin from Caesalpinia sappan in Caenorhabditis elegans," Archives of Pharmacal Research, vol. 40, no. 7, pp. 825-835, 2017.

[21] S. Losada-Barreiro and C. Bravo-Díaz, "Free radicals and polyphenols: the redox chemistry of neurodegenerative diseases," European Journal of Medicinal Chemistry, vol. 133, pp. 379402, 2017.

[22] M. Soukhtanloo, E. Mohtashami, A. Maghrouni et al., "Natural products as promising targets in glioblastoma multiforme: a focus on NF- $\kappa \mathrm{B}$ signaling pathway," Pharmacological Reports, vol. 72, no. 2, pp. 285-295, 2020.

[23] V. G. d. Q. Aquino-Martins, L. F. M. de Melo, L. M. P. Silva et al., "Antioxidante in vitro, anti-Biofilme e Atividades de Proteção Solar do Extrato de Polpa de Melocactus zehntneri (Britton \& Rose)," Antioxidants, vol. 8, no. 10, p. 439, 2019.

[24] S. L. Cartaxo, M. M. de Almeida Souza, and U. P. de Albuquerque, "Medicinal plants with bioprospecting potential used in semi-arid northeastern Brazil," Journal of Ethnopharmacology, vol. 131, no. 2, pp. 326-342, 2010.

[25] K. D. N. Magalhães, W. A. S. Guarniz, K. M. Sá et al., "Medicinal plants of the Caatinga, northeastern Brazil: Ethnopharmacopeia (1980-1990) of the late professor Francisco Jose de Abreu Matos," Journal of Ethnopharmacology, vol. 237, pp. 314-353, 2019.

[26] A. Somogyi, K. Rosta, P. Pusztai, Z. Tulassay, and G. Nagy, "Antioxidant measurements," Physiological Measurement, vol. 28, no. 4, pp. R41-R55, 2007.

[27] H. Si and D. Liu, "Dietary antiaging phytochemicals and mechanisms associated with prolonged survival," The Journal of Nutritional Biochemistry, vol. 25, no. 6, pp. 581-591, 2014.

[28] W. Chen, H. R. Lin, C. M. Wei et al., "Echinacoside, a phenylethanoid glycoside from Cistanche deserticola, extends lifespan of Caenorhabditis elegans and protects from $\mathrm{A} \beta$-induced toxicity," Biogerontology, vol. 19, no. 1, pp. 47-65, 2018.

[29] M. He, J. W. Min, W. L. Kong, X. H. He, J. X. Li, and B. W. Peng, "A review on the pharmacological effects of vitexin and isovitexin," Fitoterapia, vol. 115, pp. 74-85, 2016.

[30] H. Li, S. Pan, and X. Xu, "Structure characteristics of flavonoids for cyclooxygenase-2 mRNA inhibition in lipopolysaccharide-induced inflammatory macrophages," European Journal of Pharmacology, vol. 856, p. 172416, 2019.

[31] S. H. Jung, B. J. Kim, E. H. Lee, and N. N. Osborne, "Isoquercitrin is the most effective antioxidant in the plant _Thuja orientalis_ and able to counteract oxidative-induced damage to a transformed cell line (RGC-5 cells)," Neurochemistry International, vol. 57, no. 7, pp. 713-721, 2010.
[32] G. Grünz, K. Haas, S. Soukup et al., "Structural features and bioavailability of four flavonoids and their implications for lifespan-extending and antioxidant actions in _C. elegans_," Mechanisms of Ageing and Development, vol. 133, no. 1, pp. 1-10, 2012.

[33] A. Ganeshpurkar and A. K. Saluja, "The pharmacological potential of rutin," Saudi Pharmaceutical Journal, vol. 25, no. 2, pp. 149-164, 2017.

[34] V. S. Deepa, P. S. Kumar, S. Latha, P. Selvamani, and S. Srinivasan, "Antioxidant studies on the ethanolic extract of Commiphora spp.," African Journal of Biotechnology, vol. 8, no. 8, pp. 1630-1636, 2009.

[35] M. Compaoré, R. N. Meda, S. Bakasso, L. Vlase, and M. Kiendrebeogo, "Antioxidative, anti-inflammatory potentials and phytochemical profile of_Commiphora africana_(A. Rich.) Engl. (Burseraceae) and_Loeseneriella africana_(Willd.) (Celastraceae) stem leaves extracts," Asian Pacific Journal of Tropical Biomedicine, vol. 6, no. 8, pp. 665-670, 2016.

[36] L. J. Bischof, D. L. Huffman, and R. V. Aroian, "Assays for toxicity studies in C. elegans with Bt crystal proteins," Methods in Molecular Biology, vol. 351, pp. 139-154, 2006.

[37] S. Y. Lee and K. Kang, "Measuring the effect of chemicals on the growth and reproduction of Caenorhabditis elegans," Journal of Visualized Experiments, vol. 128, no. 128, pp. 1-5, 2017.

[38] M. Carocho and I. C. F. R. Ferreira, "A review on antioxidants, prooxidants and related controversy: natural and synthetic compounds, screening and analysis methodologies and future perspectives," Food and Chemical Toxicology, vol. 51, pp. 1525, 2013.

[39] M. L. R. Giada, "Food phenolic compounds: main classes, sources and their antioxidant Power," Oxidative Stress and Chronic Degenerative Diseases - A Role for Antioxidants, vol. 2013, pp. 87-112, 2013.

[40] A. Kampkötter, C. G. Nkwonkam, R. F. Zurawski et al., "Investigations of protective effects of the flavonoids quercetin and rutin on stress resistance in the model organism _Caenorhabditis elegans_," Toxicology, vol. 234, no. 1-2, pp. 113-123, 2007.

[41] A. Kampkötter, C. Timpel, R. F. Zurawski et al., "Increase of stress resistance and lifespan of _Caenorhabditis elegans_by quercetin," Comparative Biochemistry and Physiology. B, vol. 149, no. 2, pp. 314-323, 2008.

[42] C. Duangjan, P. Rangsinth, X. Gu, M. Wink, and T. Tencomnao, "Lifespan Extending and Oxidative Stress Resistance Properties of a Leaf Extracts from Anacardium occidentale L. in Caenorhabditis elegans," Oxidative Medicine and Cellular Longevity, vol. 2019, 16 pages, 2019.

[43] H. Peixoto, M. Roxo, H. Koolen et al., "Calycophyllum spruceanum (Benth.), the amazonian "tree of youth" prolongs longevity and enhances stress resistance in Caenorhabditis elegans," Molecules, vol. 23, no. 3, p. 534, 2018.

[44] L.,. F. M. de Melo, D. L. Gomes, L. F. da Silva et al., "Coccoloba alnifolia leaf extract as a potential antioxidant molecule using in vitro and in vivo assays," Oxidative Medicine and Cellular Longevity, vol. 2020, 12 pages, 2020. 